\title{
Vozes da Poesia Contemporânea: A dicção de Vera Lúcia de Oliveira e a Poesia do INTERDITO
}

\author{
Eduardo Dall'Alba*
}

RESUMO: O texto propõe uma leitura das temáticas da poesia de Vera Lúcia de Oliveira que tratam de morte, dor laceração e perda, condensadas em versos precisos, nos quais nenhuma palavra sobra. Dor contida e gritos emudecidos perpassam a obra e elevam sua poesia a uma dimensão trágica.

PALAVRAS-CHAVE: poesia; dor; grito; sentido.

ABSTRACT: Il testo propone una lettura delle tematiche della poesia di Vera Lúcia de Oliveira che trattano di morte, dolore, lacerazione e perdita, condensate in versi precisi nei quali nessun parola è di troppo. Dolore contenuto e grida trattenute percorrono l'opera e innalzano la sua poesia a una dimensione tragica.

PAROLE CHIAVE: poesia; dolore; grido; senso.

ABSTRACT: This text proposes a reading on the thematic of Vera Lúcia de Oliveira poems that deal with death, pain, laceration and loss condensed into precise verses where no word remains. Hidden pain and dumb screams go through her work and raise her poetry to a tragic dimension.

KEY WORD: poetry; pain; scream; sense.

* Foi pesquisador e poeta. 
1

ão raro a poesia maior emerge de uma voz distante no mapa, mas de força incontida, com o tema da morte, como em Clarice Lispector fez na prosa. A poesia da brasileira Vera Lúcia de Oliveira é lacerada pela dor e, no entanto, é capaz de se erguer como um denso corolário onde se enfeixam várias fomes. Toda é grito mudo. O grito, no entanto, vem colmado de uma escrita que avança algumas questões postas pelo cânone da poesia ocidental, adentrando num universo variado pelas mesmas vinte palavras, na exatidão de seus poemas. Nenhuma palavra sobra.

Se a temática é das difíceis: a morte, a dor, a perda, a laceração posterior a isso, a densidade do discurso não deixa espaço para a dúvida. Uma grande poeta se faz pela economia verbal e na exatidão do vocabulário que utiliza, fazendo surgir a alta poesia, seca, no limite extremo do 
sentido. Não é poesia de fluir por entre a banalidade e/ou a superfície das coisas e das pessoas, mas antes, do corte, da laceração mesma, do sentido primeiro das palavras, pretensão que logra efeito imediato na leitura dos poemas.

A distância entre as gerações, as falas e os gestos pretendidos, tudo se abarca no poema. Desse modo o primeiro poema são todos os poemas e, qualquer deles, remete ao anterior e ao posterior, porque o que fala ali é a dor e a leitura crua do mundo, em densidade exata, na palavra justa, onde não sobram migalhas de discurso retórico, como acontece em grande parte da literatura atual mundial, sobre o tema da morte:

\section{Meu Pai}

Meu pai que conheci quando se conhece a morte

e todas as mãos que deixou

Eu vivia para imaginar o gesto

esculpir o carinho

e fiquei assim com esse peso de coisa por completar

lista de compras

herança que não desemboca

árida como uma enchente

deserta como um campo de milho não semeado ${ }^{1}$

Poema e verdade poética se entrelaçam para falar da dor, coisa não comum na poesia brasileira, aproximando a poeta do discurso seco, no limite da linguagem do Sentimento do mundo, de Carlos Drummond de Andrade:

Não é triste o poema

não é triste o poeta

triste é o mundo

o mundo é que é triste ${ }^{2}$

1 Vera Lúcia de Oliveira, Geografie d'ombra, p. 16.

2 Idem, p. 54. 
Ou ainda, o que lemos é um aprendizado da dor cotidiana pela lição das quatro virtudes cardeais, que apontam para a humildade como forma de reconhecimento do humano, no poema Mas a humildade:

Ma l'umiltà non s'impara

ce l'hai

o non ce l'hai, è così

E perché uno guarda il cielo

o il mare

o seduto dinnanzi allo zio morto

e pensa

L'umiltà uno la può avere veramente

ma davanti a tutte le cose che

dissanguano il chicco

che siamo

davanti a queste cose e ad altre

l'umiltà è una cosa che fa venire voglia di imparare

lo smisurato

di imparare l'infinito

[Mas a humildade não se aprende

se tem

ou não se tem, é assim

E porque a gente olha o céu

ou o mar

ou sentado diante de um tio morto

e pensa

A humildade nós podemos tê-la de verdade mas diante de todas as coisas que dessangram o grãozinho que somos

3 Idem, p. 19 


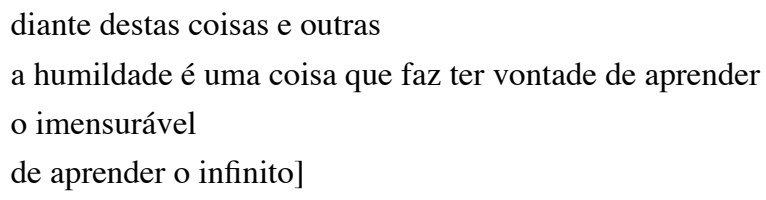

Temos aqui a concepção do mundo menor, do mundo não reconhecido, não oficial, que não está na folha do calendário e, no entanto, existe, com a força do movimento de uma Rua de Comércio:

\author{
Sou poeta da cidade magra \\ da cidade que não \\ caminha \\ sou dessa planicidade \\ sou da violência das vidas \\ poeta da cidade que afunda casas \\ e pessoas \\ sou da puta da cidade que só tem \\ superfície \\ amanheço todo dia nua e estreita \\ como uma rua de comércio.
}

Urbano mundo, onde a poeta transige com o pouco espaço, o emparedamento, o sufocamento, a superficialidade do que se oferece à visão, guardando o registro entre a aparência e a essência, no revelar-se a cidade que afunda casas e pessoas. A densidade é ali posta no engessamento ou na paralisia, pois a cidade não caminha, numa alusão ao Inferno de Dante Alighieri, onde as massas aglomeradas caminham por seus círculos, mas parecem não andar, tão numerosas são as filas de almas a ocupar os espaços que as vias parecem estreitas a Virgílio e a Dante.

Ou ainda, temos a fuga repentina da cidade, ou de um determinado espaço sufocante, onde o poema lancinante abre a porta para uma pasárgada mais crua, no poema chamado, ironicamente, Canção de ninar: 
O frio da manhã dando ferrovias

na alma

$[\ldots]$

vontade de amanhecer

na china ${ }^{4}$

No poema $O$ filho, temos a crueza e a dureza das relações familiares, onde a distância psicológica entre pai e filho è retomada pela lei do pai:
Disseram-lhe do pai
quando já estava morto
ele na cidade grande e o pai penando, não se fazia isso a um
irmão, não se deixava fora uma pessoa
só porque ela precisou deixar a própria casa
perder-se numa cidade de cão sem ninguém
não se fazia essa maldade a um filho que nunca
mais ia poder dizer pai cheguei voltei pai ${ }^{5}$

O interdito rompe a linguagem e faz do poema uma espécie de grito, uma forma de libertar a dor do não dito entre pai e filho. Simbolicamente, a linguagem da ausência se faz pelo discurso da presença do poema, que existe para aplacar a dor. Nesse sentido, a poeta constrói a base de sua poesia sobre o que está calado, sufocado, emparedado. O tema libertado pela palavra dá conta de um rio represado de conflitos. A imagem da ausência do outro, o que poderia dar afeto e resolver a fome é revelada como presença bruta e total da solidão.

Essa vivência só a poesia pode revelar, pela linguagem por tanto tempo interditada, como sinalizam as palavras do poema Natal:

a comida estava na mesa era dia de natal

a mãe com os olhos vermelhos servia o risoto

o pai comia mastigava depressa olhava o prato

a gente sentia que o frango assado parecia

de pedra de tanto que não descia

pelas nossas gargantas ${ }^{6}$

4 Idem, p. 36.

5 Vera Lúcia de Oliveira, Il denso delle cose: antologia poética, p. 86.

6 Idem, p. 88. 
A lei do pai que rege o universo familiar é sufocante no poema; a dor, revelada pelos olhos vermelhos que transformam a comida em pedra, dá conta de uma metáfora da real natureza do texto, ou seja, temos de novo a voz e o grito, mas mudos, silenciados. O poema ganha dimensão trágica, como construção de cena brechtiniana.

A poesia do interdito se estabelece como um sinal de valores onde a verdade alcança uma espécie de grau tão alto que o poema faz estralar as palavras que o compõe, tamanha condensação e força elas contêm. Esta poesia é a que alcança o que a poesia primitiva atingia quando da formação dos povos: a verdade sobre a qual se assenta a construção do mundo, sem a qual, como sem o grito, não há libertação. Daí o grau de apuro e de proximidade entre a linguagem e o que ela diz, revelando um mundo oprimido, porém ávido de redenção.

Toda - a vasta - poesia de Vera Lúcia de Oliveira é atravessada pelo calor do grito e pela dor, perfazendo os círculos internos das relações para chegar à possibilidade do entendimento da alma humana; criando uma alteridade, que ganha força à medida que avançam os poemas em que se encontra a vertente da identificação direta com o outro, ou os outros, pela fala da poeta. A identificação só é possível porque a poeta tem uma visão definida do mundo, fazendo com que a sua poesia passe ao largo da produção contemporânea e se distinga pela força dos versos que realiza. Não há gratuidade na poesia. Ela é densa e carregada do sentido mais primevo da verdade, entrecortada pelo ritmo que impregna os poemas de uma condensação extrema, cujo resultado é o próprio poema: poema que fica e que incomoda o leitor.

Os textos de Vera Lúcia de Oliveira aproximam o leitor da catarse grega do teatro. E mais não fosse, a poeta revela, pela linguagem, o interdito da cultura familiar, daquilo que durante vários anos não se pode falar. Em poema, a dor transcende e a catarse é realizada com poder de libertação, em que se estabelece um vínculo experiencial, entre a autora e o leitor. Já não como leitura apenas de fruição, mas como identificação das matrizes de um tempo que, conquanto próximo, já não existe mais. Para isso serve o poema. Para dizer do que somos feitos e para afirmar que a literatura, sobretudo a poesia, é a que condensa o maior grau de leitura da alma da humanidade, pois ela é a maior das Artes.

\section{Referências bibliográficas}

OLIVEIRA, Vera Lúcia de. Geografie d'ombra. Venezia: Fonèma Edizioni, 1989. Il denso delle cose: antologia poetica. Nardò (Lecce): Besa Editrice, 2007. 